\title{
A Study on Facebook Addiction and its Relationship with Emotional Experience and Coping Strategies
}

\author{
Md. Hassan Jafri ${ }^{1}$
}

\section{ABSTRACT}

Popularity and wide usage of Facebook has led some to its excessive use leading to the Facebook addiction which may results into several negative consequences. The present study aimed to investigate influence of Facebook addict on their emotional experiences (negative and positive emotions). The study also aimed to ascertain the influence of Facebook addicts on their coping strategies to deal with their stress. Survey was undertaken from 35 undergraduate students, taken randomly from commerce and business management of a college of Royal university of Bhutan, Bhutan. Results from regression analysis revealed that addicts experience negative emotions more than positive emotion. Similarly addicts adopted maladaptive coping strategies to deal with the stresses. The research has significant value for students, parents and educational institutions to understand negative side of excess use of Facebook and according control their usage behaviour.

Keywords: Facebook addict, Excessive usage of Facebook, Facebook and negative emotion, Facebook and coping strategies.

Facebook has become most popular among all Social Networking Sites (SNS) across the globe. According to the Facebook website, more than half of the active users log onto their accounts daily. With its possibilities such as communicating with friends, socialization, getting information about people and events, entertaining and relaxing; it is the most preferred social networking sites of the world. Teens and college students are the main users of the technology mediated communication site (Facebook) and they hangout on it frequently. With the increased popularity and wide base of Facebook, series of researches have started to understand its psychosocial influence on its users. While the Facebook has become a major source of information and communication medium for the students, the number of unhealthy or excessive Facebook use among users has also grown up. A new phenomenon has been observed among its users which are termed as Facebook Addiction. The addiction has its own repercussion on the person and the-

\footnotetext{
${ }^{1}$ Sr. Lecturer, Gaedu College of Business Studies, Royal University of Bhutan, Gedu, Bhutan.
} 
- society at large. Some studies as well as reports have highlighted the growing SNS - addiction in some parts of the world. Survey of literatures revealed that very few researches have been conducted on the Facebook addiction (Sherman, 2011; Kuss \& Griffiths, 2011). Andreassen \& Pallesen, (2013) also view that the research on SNS including Facebook is in its infancy, and as such the SNS-addiction construct needs further conceptual and empirical exploration.

\section{CONCEPTS AND LITERATURE REVIEW}

\section{Facebook Addiction}

The phenomenon of Facebook addiction is new and till date no formal definition is widely accepted. Addiction usually refers to compulsive behavior that leads to negative effects. In most addictions, people feel compelled to do certain activities so often that they become a harmful habit, which then interferes with other important activities such as work or school. The concept, social networking addiction is a phrase sometimes used to refer to someone spending too much time using social Medias such as Facebook, Twitter and other forms of social media so much so that it interferes with other aspects of daily life. However for the purpose of this research, Facebook addiction can be defined "as the excessive use of Facebook and the failure to control the usage”. Facebook addict uses the media to excess constantly checking Facebook status updates profiles, checking and / or posting messages etc., without which people feel uncomfortable.

\section{Emotions}

Emotions are reactions of person to significant events and objects. Emotions or affect can be categorized as positive and negative. Positive emotions is a mood dimensions that consists of feelings such as joy, hope, pride whereas negative emotions is a mood dimensions that consists of feelings such as anger, anxiety, shame. Positive emotions results in high achievement, greater task activity, persistence and enhanced cognitive functioning (Staw, Sutton, \& Pelled, 1994). Students experience a variety of emotions in academic settings that influence their perceptions and behavior. Researchers have revealed that student's emotions in academic settings are significantly related to students' motivation, learning strategies, cognitive resources, selfregulation, academic achievement, engagement, and personality development (Pekrun, et al., 2002; Pekrun, 2006). Researchers have indicated that types of emotions promote different styles of information processing. Positive mood facilitates creative, flexible, and holistic ways of thinking whereas more analytical, rigid, and detailed ways of processing of information can be enhanced by a negative mood (Lewis \& Haviland-Jones, 2000). Students emotions have been studied from the -perspective of anxiety and there are plethora of studies examining students' test anxiety since the 1950s (Zeidner, 2007) and has produced cumulative knowledge that have contributed in educational practice but there is little research on student emotions other than anxiety, however, implying that it is difficult to draw firm conclusions for most emotions experienced by students (Schutz \& Pekrun, 2007). 


\section{Stress Coping Strategies}

Coping strategies refer to the specific efforts, both behavioral and psychological, that people employ to control, reduce or minimize stressful events. People cope from stress in an effort to maintain their mental health and emotional well-being. People use (1) problem focused and (2) emotion - focused strategies are used to cope with the stress. problem-focused strategies, also called adaptive coping strategies refers to efforts of people to do something active to alleviate stressful circumstances, whereas emotion-focused coping which is also called maladaptive coping strategies involve efforts to regulate the emotional consequences of stressful or potentially stressful events such as crying or venting frustration in some way, or participating in activities designed to alter mood, such as dancing or using humor or comedy (Monat \& Lazarus, 1991). According to Folkman \& Lazarus (1980), people use both types of strategies to combat most stressful events.

\section{Facebook Use and its Impact}

Researchers have revealed the implications of the use of Facebook on such areas as relationship- formation and satisfaction (Sheldon, Abad, \& Hinsch, 2011); identity construction (Back et al., 2010); psychological and emotional wellbeing (Valkenburg, Peter, \& Schouton, 2006), learning (Kabilan, Ahman, \& Abidin, 2010); and privacy (Gross \& Acquisti, 2005). Social network sites induce positive emotional experiences (Mauri, et al., 2011). Facebook could be a great tool to connect with family and friends and develop and maintain relationships, exchange information etc. But if a person are unable to concentrate properly on his daily normal activities because of the continuous thinking about going online then that's a sign of trouble. How Facebook addiction impacts on person's physiological, social and psychological life is not clear yet as the research on this area has started recently. The small number of studies conducted so far on the SNS including Facebook, suggests that SNS-addiction is associated with healthrelated, academic, and interpersonal problems/issues (Andreassen \& Pallesen, 2013). Excessive use of Facebook is associated with jealousy, social tension, isolation and depression, several researches revealed (The Economist, Aug. 17, 2013). In a longitudinal research conducted recently by Ethan Kross of the University of Michigan and Philippe Verduyn of Leuven University in Belgium on 82 Facebookers who were in their late teens or early 20s to track how their emotions change with the use of Facebook, their study revealed that those who used Facebook a lot were more likely to report a decline in satisfaction than those who visited the site infrequently (The Economist, Aug. 17, 2013). Of the 26\% reporting an impact of their usage on their lives, three-quarters (74\%) claimed that it had a negative impact, including procrastination, distraction, and poor time-management. Researchers have found that compulsive SNS (including Facebook) usage is related to loneliness, missing of work, school, and real world social activities (LaRose et al. , 2010), and negatively related to psychological well being among college freshmen but not among older students (Kalpidou, Costin, \& Morris, 2011). Extrapolating direct and indirect findings of earlier researches and also extending on other variables, it can be said that Facebook addiction can lead negative emotional experiences and also can lead to 
maladaptive coping strategies from stress. Thus following hypotheses were formulated for the study -

$\mathrm{H} 1$ : Facebook addiction is positively and significantly related to negative emotional experience

$\mathrm{H} 2$ : Facebook addiction is positively and significantly related to maladaptive coping strategies

\section{METHOD}

The present study is based on cross-sectional design and primary research method is used to collect the required information to test hypotheses of the study.

\section{Sample and Procedures}

The present study is conducted on undergraduate business and commerce students of a college of Royal university of Bhutan. The study was undertaken in two stages. In the first stage, Facebook addiction scale was used to identify addicted students. The scale was administered on a total of 400 students, taken randomly and out of that 35 students were identified as addicted. The identification was done based on the criteria provided by Andreassen et al., (2012).

In the second stage of the study, identified students were administered other two scales emotional experience and coping strategies. The respondents ranged between 18 and 26 years in age. All the respondents were having their active Facebook account. Data were collected from respondents during college hours and the questionnaire was completed in the presence of the researcher. All the necessary information regarding the study objectives and ways to respond on questionnaire were shared with all respondents. Respondents were assured of confidentiality of their responses and were told that their responses shall be used for the research purpose only.

\section{Measures}

Bergen Facebook Addiction Scale - In order to measure Facebook addiction, the scale developed by Andreassen et al., (2012) is used. Responses on the scale were rated on a 5-point scale indicating (1) Very rarely, (2) Rarely, (3) Sometimes, (4) Often, and (5) Very often. The scale has six items and its reliability in the present sample is found to be 0.68 (alpha). Andreassen et al., (2012) suggest that scoring "often" or "very often" on at least four of the six items may suggest the respondent is addicted to Facebook.

The Scale of Positive and Negative Experience (SPANE) - The scale consists of a 12item which includes six items to assess positive feelings and six items to assess negative feelings. The scale was developed by Diener et al., (2010). Responses were taken on 5-point scale ranging (1) Very rarely / Never, to (3) Sometimes, to (5) Very often / Always. The scale has reliability 0.67 (alpha). 
Coping Strategies- In order to assess students coping strategies, items were taken from the COPE Inventory developed by Carver, Scheier \& Weintraub (1989). The scale has 60 items covering from 15 areas. But in the present research only two areas / ways of coping - problem focused and emotion focused coping strategies, have been taken which has 4 items each. Responses were taken on 4-points scale ranging from (1) I usually don't do this at all, (2) I usually do this a little bit, (3) I usually do this a medium amount, and (4) I usually do this a lot. Reliability of the scale is found to be 0.72 (alpha) in the present sample.

\section{RESULTS AND ANALYSIS}

As the study aimed to see the influence of Facebook addiction on positive and negative emotional experience and also on coping strategies, correlation and multiple regression analysis were carried out to test the hypotheses.

Table 1: Summary of Regression Analysis for Positive and Negative Emotional Experience as a function of Facebook addict

\begin{tabular}{|c|c|c|}
\hline $\begin{array}{l}\text { Types Emotional } \\
\text { Experiences }\end{array}$ & • & \\
\hline \multirow{6}{*}{$\begin{array}{l}\text { Positive Emotional } \\
\text { Experience }\end{array}$} & $\mathrm{R}$ & 0.25 \\
\hline & R Square & 0.09 \\
\hline & Adjusted R Square & 0.08 \\
\hline & Standard Error of estimate & 2.27 \\
\hline & F- Value & $5.20 * *$ \\
\hline & Level of Significance & .02 \\
\hline \multirow{6}{*}{$\begin{array}{c}\text { Negative Emotional } \\
\text { Experience }\end{array}$} & $\mathrm{R}$ & 0.44 \\
\hline & R Square & 0.31 \\
\hline & Adjusted R Square & 0.27 \\
\hline & Standard Error of estimate & 7.72 \\
\hline & F- Value & 10.89* \\
\hline & Level of Significance & .000 \\
\hline
\end{tabular}

* Significant at $\mathrm{p}<0.01$ level (2-tailed).

** Significant at $\mathrm{p}<0.05$ level (2-tailed). 
Results presented in the above table shows that Facebook addicts experience negative emotion significantly. $\mathrm{R}^{2}$ for addicts experiencing negative emotions is found to be 0.31 , which indicates that around 31 percent of variance in negative emotion is being explained by Facebook addiction. F values with 10.89 corroborates this as it is found to be significant $(p=.000)$. Thus, hypothesis 1, which predicted Facebook addiction is positively and significantly influences negative emotional experience, was supported.

Table 2: Summary of Regression Analysis for Adaptive and Maladaptive Coping Strategies as a function of Facebook addict

\begin{tabular}{|c|c|c|}
\hline Types of Coping Strategies & & \\
\hline \multirow[t]{6}{*}{ Adaptive Coping Strategies } & $\mathrm{R}$ & 0.13 \\
\hline & R Square & 0.08 \\
\hline & Adjusted R Square & 0.05 \\
\hline & Standard Error of estimate & 1.04 \\
\hline & F- Value & 1.55 \\
\hline & Level of Significance & 2.15 \\
\hline \multirow{6}{*}{$\begin{array}{c}\text { Maladaptive Coping } \\
\text { Strategies }\end{array}$} & $\mathrm{R}$ & 0.42 \\
\hline & R Square & 0.18 \\
\hline & Adjusted R Square & 0.14 \\
\hline & Standard Error of estimate & 2.23 \\
\hline & F- Value & $10.49 *$ \\
\hline & Level of Significance & 0.002 \\
\hline
\end{tabular}

* Significant at $\mathrm{p}<0.01$ level (2-tailed).

** Significant at $\mathrm{p}<0.05$ level (2-tailed).

Results presented in the above table (table 3) shows that Facebook addicts adopts maladaptive coping strategies when faced with stressful situations significantly. $\mathrm{R}^{2}$ for addicts for using maladaptive coping strategies is found to be 0.18 , which indicates that around 18 percent of variance in using maladaptive coping strategies is being explained by Facebook addiction. F values with 10.49 corroborates this as it is found to be significant $(p=.002)$. Thus, hypothesis 2, which predicted Facebook addiction is positively and significantly related to maladaptive coping strategies, was supported. 


\section{DISCUSSION}

The present study aimed to achieve two objectives - (1) to explore that Facebook addiction can lead to negative emotional experiences and (2) Facebook addiction can results into maladaptive coping strategies from stress.

With respect to the emotional experience, it is found in the study that addiction to Facebook leads to the negative emotional experience. The present finding is in lined with the findings which found that people who use social media heavily experiences different kind of negative emotions. Reason for the negative emotional experiences could be that during or after the usage addicts realize that they gained nothing of the time they killed in Facebook rather they lost so many things. They realize that they are not able to meet their daily life requirements as effectively and efficiently as non-addicts colleagues. This may also leads to lower academic and social performance and at some point of time addicts realize this fact and this leads to negative emotional experiences.

The result of the study made clear that Facebook addicts resort to the maladaptive / emotion focused coping strategies. One reason for this could be that addicts are preoccupied with going online and don't give time to think about the issues in concrete form and that is why they take emotional approach of dealing with the stress. Another reason could be the fact that mood determines individual's thinking and judgment and because addicts experiences negative emotions and that is why probably in this kind of emotional experiences addicts are not able to think about the real issue genuinely and objectively. This may resort to maladaptive or emotional approach of coping when pressed with the issue.

\section{CONCLUSIONS AND IMPLICATION}

Addiction of Facebook has taken researchers to explore various issues related to its use. The present study and findings are in line of it and showed that those who become addict of the Facebook usage doesn't feel happy and joy rather ends up with several negative emotional experiences such as sadness, unhappiness, etc. Those who always want to go online and indulge themselves with the Facebook ends up with negative feelings and emotions. This in turn may leads to several negative consequences such as poor academic or work performance, reduced social relations, decreased family engagement etc. Further it is also found in the study that addicts of Facebook fail to deal with the life demands objectively, don't adopt the problem centered approach in dealing with the stress or stressful situation. Rather such people adopt maladaptive or emotion focused approach which may always not be good.

The study has both practical and theoretical implication. Insights gained from the study can be used by parents and school and college administration to educate their teens and students about the various positive and negative sides of the SNS site especially Facebook and its usage pattern. Education provides awareness which helps in developing a sense of right and wrong of behaviour. 


\section{LIMITATIONS AND FUTURE RESEARCH}

The study has several limitations, so findings of this study should be taken with caution. One of the limitations is the small sample size which has the limited generalizability. Future research should include more sample size. Another limitation is that the study is based on self report survey which may be affected by the biasness, thus affecting the research outcome. Further cross sectional design is used in the study which is another limitation. Better insights can be gained on the issue by using longitudinal research. The concept of Facebook addiction is still in developing stage, and firm criteria for the addiction is not widely agreed and so difficult to say about the Facebook addiction with certainty. Taking all these limitations in to account, the author recommends undertaking further research in order to have more meaningful insight of Facebook addiction and its influence on emotions and coping strategies.

\section{REFERENCE}

Andreassen CS, Pallesen S. (2013). Social Network Site Addiction - An Overview. Retrieved on 26, Nov. 2013 from http://www.ncbi.nlm.nih.gov/pubmed/24001298

Andreassen, C.S.; Torsheim, T.; Brunborg, G.S \& Pallsen, S. (2012) Development of a Facebook Addiction Scale. Psychological Reports: 110 (2), 501-517.

Back, M. D., Stopfer, J. M., Vazire, S., Gaddis, S., Schmukle, S. C., Egloff, B., \& Gosling, S. D. (2010). Facebook profiles reflect actual personality, not self-idealization. Psychological Science, 21(3), 372-374.

Carver, C. S., Scheier, M. F., \& Weintraub, J. K. (1989). Assessing coping strategies: A theoretically based approach. Journal of Personality and Social Psychology, 56, 267-283.

Diener, E., Wirtz, D., Tov, W., Kim-Prieto, C., Choi, D.W., Oishi, S., \& Biswas-Diener, R. (2010). New well-being measures: Short scales to assess flourishing and positive and negative feelings. Social Indicator Research, 97, 143-156.

Folkman, S., \& Lazarus, L. S. (1980). An analysis of coping in a middle-aged community sample. Journal of Health and Social Behavior, 21, 219-239.

Kabilan, M. K., Ahmad, N., \& Abidin, M. J. Z. (2010). Facebook: An online environment for learning of English in institutions of higher education?. Internet \& Higher Education, 13(4), 179-187.

Kalpidou, M., Costin, D., \& Morris, J. (2011). The relationship between Facebook and the wellbeing of undergraduate college students. Cyber Psychology, Behavior, and Social Networking, 14(4), 183-189.

Kuss DJ, Griffiths MD. (2011). Addiction to social networks on the internet: A literature review of empirical research. International Journal of Environment and Public Health, 8, 35283552

.LaRose, R., Kim, J.H., \& Peng, W., (2010). Social Networking: Addictive, Compulsive, Problematic, or Just Another Media Habit? In A Networked Self: Identity, Community, and Culture on Social Network Sites (Z. Pappacharissi, Ed.), NY: Routledge, pp 59-81.

Lewis, M., \& Haviland-Jones, J. M. (2000). Handbook of emotions. New York: Guilford Press. 
Mauri, M., Cipresso, P., Balgera, A., Villamira, M., \& Riva, G. (2011). Why is Facebook so successful? Psycho-physiological measures describe a core flow state while using Facebook. Cyber-psychology, Behavior, and Social Networking, 14(12), 723-731.

Monat A, \& Lazarus R. (1991). Stress and Coping: An Anthology, (3rd Ed.), New York: Columbia University Press.

Pekrun, R., Goetz, T., Titz, W., \& Perry, R. P. (2002). Academic Emotions in Students' SelfRegulated Learning and Achievement: A Program of Qualitative and Quantitative Research. Educational Psychologist, 37 (2), 91-105.

Pekrun, R. (2006). The Control-Value Theory of Achievement Emotions: Assumptions, Corollaries, and Implications for Educational Research and Practice. Educational Psychology Review, 18, 315-341.

Sheldon, K. M., Abad, N., \& Hinsch, C. (2011). A two-process view of Facebook use and relatedness need-satisfaction: Disconnection drives use, and connection rewards it. Journal of Personality and Social Psychology, 100 (4), 766-775.

Sherman, E. (2011). "Facebook Addiction: Factors Influencing an Individual's Addiction". Honors Thesis Program in the College of Management. Scholar Works at UMass Boston. Paper 5.

Staw, B.M., Sutton, R. S., Pelled, L.H. (1994). Employee positive emotion and avorable outcomes at the workplace. Organization Science, 5(1), 51-70.

Schutz, P. A., \& Pekrun, R. (2007). Emotion in education. San Diego, CA: Academic Press.

The Economist (Aug 17th 2013). Using the social network seems to make people more miserable. Retrieved on $28^{\text {th }}$ Nov, 2013 from http://www.economist.com/news/scienceand-technology/21583593-using-social-network-seems-make-people-more-miserable-getlife

Valkenburg, P. M., Peter, J., \& Schouten, M. A. (2006). Friend networking sites and their relationship to adolescents' well-being and social selfesteem. Cyber Psychology \& Behavior, 9, 584- 590.

Zeidner, M. (2007). Test anxiety in educational contexts: Concepts, Findings, Future directions, I n p, A, Schutz \& R. Pekrun (Eds,l). Emotion in education (pp. 1 59- 1 77). San Diego: Elsevier Inc, 